\title{
2D OVERTOPPING AND IMPACT EXPERIMENTS IN SHALLOW FORESHORE CONDITIONS
}

\author{
Vincent Gruwez ${ }^{1}$, Ine Vandebeek ${ }^{1,2}$, Dogan Kisacik ${ }^{3}$, Maximilian Streicher ${ }^{1}$, Corrado \\ Altomare ${ }^{1,4}$, Tomohiro Suzuki ${ }^{4}$, Toon Verwaest ${ }^{4}$, Andreas Kortenhaus ${ }^{1}$ and Peter Troch ${ }^{1}$
}

\begin{abstract}
This paper introduces the 2D experiments conducted for the CREST project in the wave flume of Ghent University. The experiments focus on wave interactions with low-crested sea dikes fronted by a shallow foreshore and mildly to steeply sloping beaches, which is a very typical situation along the Belgian coast. Foreshore slopes of $1 / 20,1 / 35,1 / 50$ and $1 / 80$ were tested for a range of low to high energy wave conditions, a variation in wave steepness and two water levels. The main goal was to obtain a dataset in which the effects of the infragravity waves on the wave-structure interactions (i.e. wave overtopping and impact forces) can be studied. The tests included high spatial resolution surface elevation measurement tests, which is new for beaches including a dike in the inner surf zone. From the first results it became clear that the foreshore slope influences the wave transformation up to the dike toe. The influence is apparent comparing to existing (semi-) empirical models for prediction of the spectral wave period at the dike toe and wave overtopping at the dike crest. The high spatial resolution data show a steep increase in infragravity significant wave height in the very shallow area in front of the dike.
\end{abstract}

Keywords: physical experiment; wave transformation; wave overtopping; overtopped wave impact force; very shallow foreshore; infragravity waves

\section{INTRODUCTION}

Wave-interactions with sea dikes and storm walls (e.g. reflection, wave run-up, overtopping, forces, etc.) at deep and intermediate water depths have already been extensively investigated (Van der Meer et al., 2016). Research on such interactions with dike structures on a very shallow and mildly sloping foreshore is much sparser. Increased interest in e.g. Belgium and the Netherlands exists for this case (Altomare et al., 2016), since most of the coastal urban areas are fronted by such a coastal defense system. Lacking relevant experimental data, current methodologies to design this type of defense are still uncertain. Within the research project CREST - Climate REsilient coaST (VLIZ, 2018), one of the main objectives is to establish a prediction methodology (using advanced numerical models supported by physical models and field measurements) for wave overtopping and wave impact forces on sea defenses for this specific case.

Wave dynamics on mildly sloping beaches determine in large part the morphodynamics of the beach. That is why it has recently been studied more actively by conducting surface elevation measurements at a high number of locations along the beach, up to and, in some cases, including the swash zone (Boers et al., 1996; van Dongeren et al., 2007; Ruessink et al., 2013). This allowed a detailed analysis of the wave dynamics, in particular the non-linear wave interactions and the behavior of the infragravity waves. However, what is still unexplored is what happens when an impermeable steep-sloped dike is placed in the inner surf zone close to the swash zone on such a mildly sloping beach, both in terms of impact on the wave dynamics over the beach and the wave-structure interactions with the dike. The study of that situation requires the combination of currently two separate fields of study: (1) the study of cross-shore wave transformation and hydrodynamics over a beach and (2) the study of wave overtopping and wave impact forces on an impermeable steep-sloped dike. Therefore, in addition to overtopping and wave impact force measurements, a high spatial resolution dataset of surface elevations along the foreshore was generated. This is both useful to validate numerical models, but also allows a wave-by-wave analysis of the surf zone hydrodynamics.

The wave conditions at the toe of the dike in case of very to extremely shallow foreshores are known to be dominated by low-frequency (or infragravity) waves. To aid the design of such dike structures, Hofland et al. (2017) have provided a first empirical model for predicting the spectral wave period $T_{m-1,0}$ at the toe of a dike with a mildly sloped and shallow foreshore. However, the applicability to steeper foreshore slopes was not yet investigated. These steeper slopes were included in the test program of the presented experiments.

This paper provides an overview of the $2 \mathrm{D}$ experimental small scale modelling conducted in the wave flume of Ghent University, followed by some first results and observations. The main objectives

\footnotetext{
${ }^{1}$ Department of Civil Engineering, Ghent University (UGent), Technologiepark 904, Ghent, 9052, Belgium

${ }^{2}$ Department of Civil Engineering, KU Leuven, Kasteelpark Arenberg 40, Leuven, 3001, Belgium

3 Institute of Marine Sciences and Technology, Dokuz Eylül University, H. Aliyev Boulevard 32, Izmir, 35340, Turkey

${ }^{4}$ Flanders Hydraulics Research, Berchemlei 115, Antwerp, 2140, Belgium
} 
of the experiments presented, are summarized as follows: (1) providing data for the validation of the numerical models being developed within the CREST project, (2) investigate the effect of the foreshore slope on both the wave transformation up to the dike toe and (3) the wave-structure interactions (i.e. overtopping and forces). The experiments consisted therefore of three main types of tests: tests with a high spatial resolution (HSR) positioning of wave gauges, wave overtopping tests (OVT) and wave impact force tests (WIF).

\section{EXPERIMENTAL MODEL}

\section{Model set-up}

The small-scale experiments were carried out in the $30.0 \mathrm{~m}$ long, $1.0 \mathrm{~m}$ wide and $1.2 \mathrm{~m}$ high wave flume of the Coastal Engineering Research Group, Department of Civil Engineering at Ghent University. It has a piston-type wave maker controlled by both in-house developed software for first-order wave generation with Active Wave Absorption (AWA), and the AwaSys7 software (Aalborg University, 2018a) for second-order wave generation, including AWA.

The geometry of the modelled cross-shore profiles consisted of a dike fronted by a very shallow foreshore. The selection of foreshore slopes was based on the range of actual foreshore slopes occurring along the coast of Belgium (i.e. 1/20 - 1/90). A beach slope of $\sim 1 / 35-1 / 40$ is often stated as being a limit between steeply and mildly (or low) sloping beaches (Ruessink et al., 2013; Hofland et al., 2017) for the energetic wave conditions during storms along the coasts of North-West Europe. The difference between both types of slopes is that the wave non-linearity has a different character. Even if the foreshore is considered to be very shallow, this mostly pertains to the water depth at the toe of the dike and not to the non-linearity behavior over the foreshore slope. The range of tests here covers both steep foreshores and mildly sloped foreshores to cover the complete range of non-linearity behavior in combination with the very shallow foreshore in front of the dike.

The dike had a $1 / 2$ slope, followed by a $1 / 50$ sloped promenade over $20 \mathrm{~m}$ (prototype) and a vertical, non-overtoppable wall. Model scales 1:25 and 1:35 were used to be able to accommodate foreshore slopes between $1 / 20$ and $1 / 80$ in the wave flume (see Fig. 1), thereby covering the range of slopes actually present along the Belgian coast. The end of the foreshore slope was connected to the flume bottom by a $1 / 10$ transition slope. This transition ended approximately $0.05 \mathrm{~m}$ above the bottom to allow a connection with the return flow channel along the bottom of the flume. Foreshore slope 1/50 was modelled in both scales to be able to take into account the differences due to scale effects.

The dike and transition slopes were built using smooth plywood, whereas the fixed bed foreshore was built up with bricks that supported a wooden frame. This was finished with a top layer of a sandcement mixture levelled to the required slope (see Fig. 2a). In the very shallow part of the foreshore slope up to the dike toe, a small trough was created in the middle of the flume width by an aluminum u-profile embedded in the screed top-layer. This was necessary to be able to flush mount the wave gauges and perform measurements with them in this area.

A separation wall was installed over approximately $8.0 \mathrm{~m}$ from the dike toe dividing the flume locally over this length into two channels (see Fig. 2a): a main channel $0.75 \mathrm{~m}$ wide and a small channel $0.25 \mathrm{~m}$ wide (see Fig. 2e). Kamphuis (1998) investigated the effects of the length of a separation wall (i.e. $27 \mathrm{~m}$, $18 \mathrm{~m}$ and $9 \mathrm{~m}$ over a foreshore slope of 1/50) on the long wave energy at the toe of the dike and found none. In the main channel, the dike slope was always present. Consequently, it is where the wave overtopping (see Fig. 2d) and wave impact force measurements (see Fig. 2c) were conducted. In the small channel no dike was constructed, but instead a horizontal levelling-off at the dike toe level was installed (see Fig. 2e). The horizontal part ended in dissipative material, limiting the wave reflection as much as possible. The purpose of the small channel was to be able to measure the incident wave conditions (IWC) at the toe of the dike, simultaneously with each overtopping and wave force test. For foreshore slopes 1/50 (at model scale 1:35) and 1/35 (at model scale 1:25), this small channel set-up was extended over the complete flume width for a couple of tests to be able to investigate its performance. Conversely, the dike geometry, including promenade and vertical wall, was constructed over the complete flume width for the HSR tests. This was done to obtain a correct behavior in the flume of the wave reflection against the dike, and therefore to be able to make unambiguous measurements of the surface elevations along the complete length of the foreshore (before and after the end of the separation wall).

\section{Test program and wave generation}

Table 1 provides an overview of all the test conditions (values at scale 1:25). The main test program consisted of random waves with correct reproduction of second order bound sub and super harmonics 
(RS). The generated offshore significant wave height $H_{m 0, o}$ and peak wave period $T_{p, o}$ were varied to represent low-, intermediate and high-energy sea states. Two water levels were tested: $+7.00 \mathrm{~m}$ TAW and $+8.00 \mathrm{~m}$ TAW (both are prototype values and TAW is a Belgian reference level), represented by water depths at the wave paddle $h_{o}$ of $0.65 \mathrm{~m}$ and $0.69 \mathrm{~m}$ respectively (at scale 1:25).
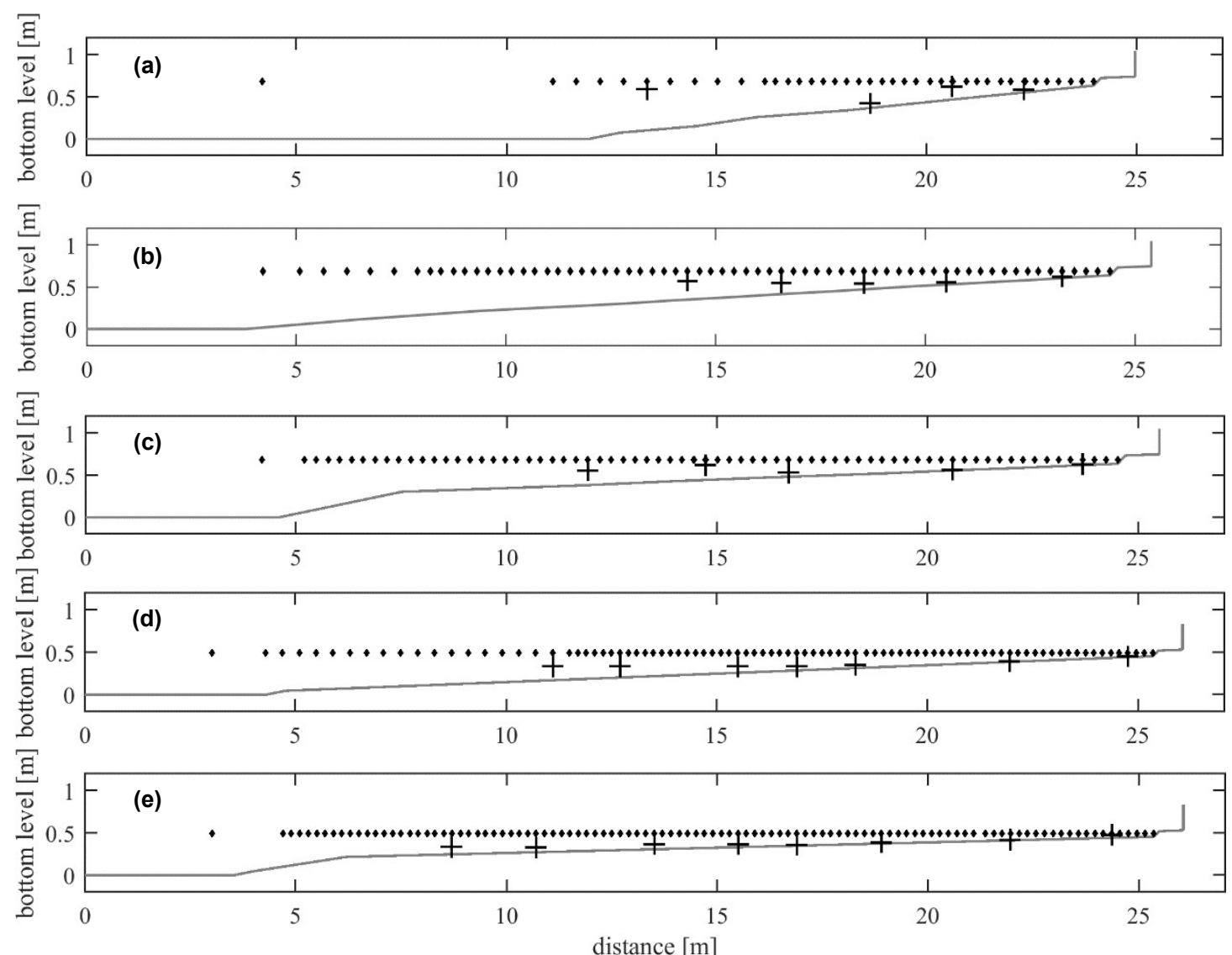

Figure 1. Tested cross-shore bottom profiles, consisting of a dike geometry with foreshore slopes: (a) 1/20 (model scale 1:25), (b) 1/35 (scale 1:25), (c) 1/50 (scale 1:25), (d) 1/50 (scale 1:35), and (e) 1/80 (scale 1:35). Bed level $z$ (flume bottom at $z=0.0 \mathrm{~m}$ ) is shown by the grey line over the cross-shore distance $x$ from the wavemaker zero position $(x=0.0 \mathrm{~m})$. The wave gauge positions (diamonds) are plotted at the highest water level tested and the plusses are the positions and heights of the electromagnetic current meter for the high spatial resolution tests.

All generated surface elevation time series were derived by an inverse FFT from a JONSWAP spectrum with peakedness factor $\gamma$ of 3.3. The wave phases were determined randomly (deterministic method), but with a fixed seed number to obtain the same wave phase combinations for all conditions over all tested foreshore slopes. The duration of the tests was usually 1000 waves long, with some exceptions due to time constraints.

The most energetic conditions tested (RS01), in combination with the lowest tested water level, represent the nearshore wave conditions expected during a super storm of return period 1000 years. These are the official design and safety check conditions for sea defense structures along the Belgian coast (MDK - Coastal Division and FHR, 2011). In test condition RS05, the significant wave height was lowered compared to RS01 to a value which is estimated to closely representing the real (in a 3D environment) long wave energy content at the toe of the dike. This was done as a way to take into account the effect of directional spreading on the amount of wave energy transfer to the infragravity wave band over a very shallow foreshore in a 2D wave flume (Suzuki et al., 2014). This is further explored in the 3D wave basin tests conducted for the CREST project (Altomare et al., 2018). The other test conditions were chosen in such a way that a range of relative water depths $\left(h_{t} / H_{m 0, o}\right)$ at the toe of the dike was obtained relevant for comparison to the prediction formula of Hofland et al. (2017) (i.e. 0.06 - 1.30, from extremely shallow to shallow foreshore depths). Similarly, the test conditions provide a broad range of mean overtopping discharges for comparison to the prediction formula of Altomare et al. (2016). 
(a)

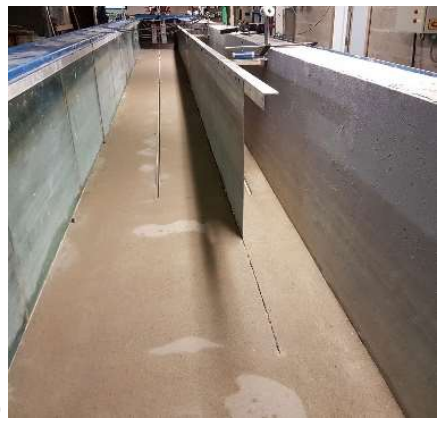

(b)

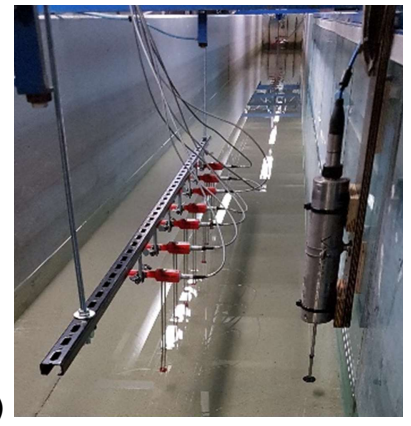

(c)

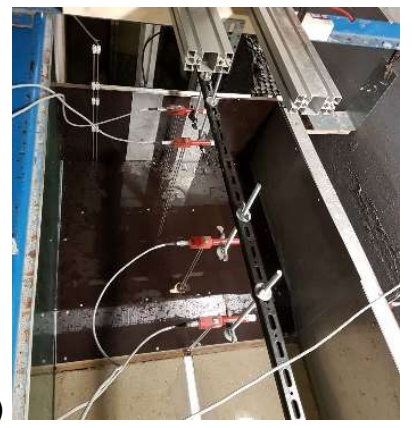

(e)

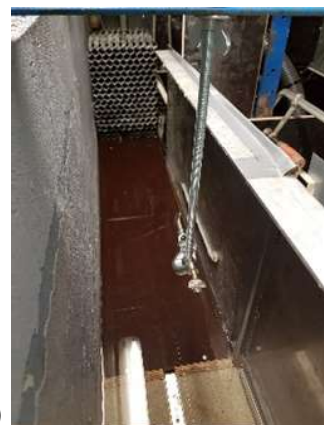

(f)

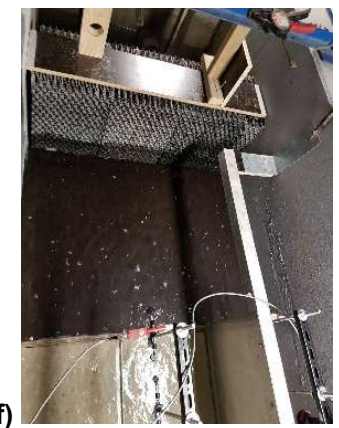

Figure 2. Model set-up pictures: (a) view on the 1/50 foreshore slope and separation wall towards the dike, (b) first array of 7 wave gauges and one co-located ECM for the high spatial resolution tests, (c) model set-up for wave impact measurements, (d) wave overtopping set-up, (e) view on the small separated channel with absorption material, and (f) model set-up for the incident wave conditions at the toe of the dike.

All sea states were tested for the OVT and WIF experiments, except for some conditions where no wave impacts were expected to occur in case of the WIF tests. Because of the many repeated tests necessary for the HSR experiments, the tested conditions were limited to three, conducted for both water levels, providing results for six hydrodynamic conditions. In addition, the test duration was reduced from $\sim 1000$ waves to $\sim 100$ waves for four of those six conditions. IWC experiments were only done for foreshore slope 1/50 at model scale 1:35 and foreshore slope 1/35 at model scale 1:25 (not indicated in Table 1).

It was already established that infragravity waves play an important role at the toe of a dike with a very shallow foreshore. Therefore, to be able to realistically represent the long waves at the toe of the dike, second-order wave generation was used for this study, so that spurious free sub (and super) harmonics were suppressed. The AWA-system used by the AwaSys7 software requires a wave gauge mounted on the wave maker face, providing control of the generated waves when performing model tests where reflections are significant, with broad banded absorption capabilities for irregular waves (Lykke Andersen et al., 2016). The user specifies the range of frequencies, defined by a low and high cut-off frequency, between which the AWA-system is most effective. The bounds of this range are limited by and depend on the wave conditions to be generated and the characteristics of the wave maker, such as the available stroke length of the paddle. The relatively long available stroke length (i.e. $1.40 \mathrm{~m}$ ) allowed a low value for the low cut-off frequency: within the range of $0.021-0.050 \mathrm{~Hz}$ for the generated conditions. This caused the AWA-system to absorb most of the reflected infragravity waves, preventing their re-reflection at the paddle. Depending on the geometry of the foreshore, the first mode seiche was calculated to be between $0.020-0.040 \mathrm{~Hz}$. So those low attained values for the low cut-off frequency also prevented excessive build-up of seiche energy in the flume. Finally, the AWA-system was kept active for five minutes after the end of each test to allow the system to absorb the remaining reflected waves and therefore help make the water still again as quickly as possible for the next test.

In addition to the second order generated random waves, some tests were repeated on the 1/35 and 1/50 foreshore (scale 1:25) using first order wave generation (RF) to investigate the effect on the wave transformation and individual wave overtopping (see Table 1). 


\begin{tabular}{|c|c|c|c|c|c|c|c|c|c|}
\hline \multicolumn{10}{|c|}{$\begin{array}{c}\text { Table 1. Test program for the 2D CREST experiments (values provided for scale 1:25). RS(F): Random } \\
\text { Second (First) order wave generation, HSR: high spatial resolution test, OVT: (individual) wave overtopping } \\
\text { test, WIF: wave impact force test. }\end{array}$} \\
\hline Test ID & Order & $h_{o}$ & $H_{m 0, o}$ & $T_{p, o}$ & $\cot (\theta)$ & $h_{t} / H_{m 0, o}$ & HSR & OVT & WIF \\
\hline$[-]$ & {$[-]$} & [m] & {$[\mathrm{m}]$} & [s] & {$[-]$} & {$[-]$} & {$[-]$} & {$[-]$} & {$[-]$} \\
\hline RS01 & $2^{\text {nd }}$ & 0.65 & 0.20 & 2.4 & $20,35,50$ (1:25), 50 (1:35), 80 & 0.06 & No & Yes & Yes \\
\hline RF01 & $1^{\text {st }}$ & 0.65 & 0.20 & 2.4 & $35,50(1: 25)$ & 0.06 & No & Yes & Yes \\
\hline RS02 & $2^{\text {nd }}$ & 0.65 & 0.20 & 2.0 & $20,35,50$ (1:25), 50 (1:35), 80 & 0.06 & Yes* $^{*}$ & Yes & No \\
\hline RS03 & $2^{\text {nd }}$ & 0.65 & 0.20 & 1.6 & $20,35,50$ (1:25), 50 (1:35), 80 & 0.07 & No & Yes & No \\
\hline RS04 & $2^{\text {nd }}$ & 0.65 & 0.12 & 1.6 & $20,35,50(1: 25), 50(1: 35), 80$ & 0.10 & Yes* & No & No \\
\hline RS05 & $2^{\text {nd }}$ & 0.65 & 0.08 & 2.4 & $20,35,50$ (1:25), 50 (1:35), 80 & 0.15 & Yes & Yes & Yes \\
\hline RF05 & $1^{\text {st }}$ & 0.65 & 0.08 & 2.4 & $35,50(1: 25)$ & 0.15 & Yes & Yes & Yes \\
\hline RS06 & $2^{\text {nd }}$ & 0.69 & 0.20 & 2.4 & $20,35,50$ (1:25), 50 (1:35), 80 & 0.26 & Yes* & Yes & Yes \\
\hline RS07 & $2^{\text {nd }}$ & 0.69 & 0.20 & 2.0 & $20,35,50(1: 25), 50(1: 35), 80$ & 0.26 & No & Yes & Yes \\
\hline RS08 & $2^{\text {nd }}$ & 0.69 & 0.20 & 1.6 & $20,35,50(1: 25), 50(1: 35), 80$ & 0.26 & No & Yes & Yes \\
\hline RS09 & $2^{\text {nd }}$ & 0.69 & 0.12 & 1.6 & $20,35,50(1: 25), 50(1: 35), 80$ & 0.43 & Yes* & Yes & Yes \\
\hline RS10 & $2^{\text {nd }}$ & 0.69 & 0.12 & 2.4 & $20,35,50(1: 25), 50(1: 35), 80$ & 0.43 & No & Yes & Yes \\
\hline RS11 & $2^{\text {nd }}$ & 0.69 & 0.08 & 2.4 & $20,35,50$ (1:25), 50 (1:35), 80 & 0.65 & Yes & Yes & Yes \\
\hline RF11 & $1^{\text {st }}$ & 0.69 & 0.08 & 2.4 & $35,50(1: 25)$ & 0.65 & No & Yes & Yes \\
\hline RS12 & $2^{\text {nd }}$ & 0.69 & 0.06 & 2.4 & $20,35,50(1: 25), 50(1: 35), 80$ & 0.87 & No & Yes & Yes \\
\hline RS13 & $2^{\text {nd }}$ & 0.69 & 0.04 & 2.4 & $20,35,50(1: 25), 50(1: 35), 80$ & 1.30 & No & Yes & Yes \\
\hline
\end{tabular}

*short test: $\sim 100$ waves instead of $\sim 1000$ waves

Also, a limited set of short duration ( 20 waves) bichromatic wave tests were done on foreshore slopes $1 / 35$ and 1/50 (scale 1:25) to provide an initial and less complex validation dataset for the numerical models and to allow analysis of a single bound long wave (see Table 2). The frequencies of both wave components were kept constant, so that the bound long wave frequency $\left(f_{3}=f_{2}-f_{l}\right)$ stayed constant and the mean frequency $f_{m}=\left(f_{1}+f_{2}\right) / 2$ was equal to the peak frequency of most of the RS tests (i.e. $0.419 \mathrm{~Hz}$ ). The sum of the amplitudes $a_{1}$ and $a_{2}$ was chosen to be $0.10 \mathrm{~m}$, because of $H_{m 0, o}=0.20 \mathrm{~m}$ for the highest energy condition, and were changed once to increase the group modulation $\delta\left(=a_{2} / a_{1}\right)$. These choices are similar to those made in the work by Ruessink et al. (2013).

\begin{tabular}{|c|c|c|c|c|c|c|c|c|c|c|c|c|}
\hline Test ID & Order & $h_{0}$ & $a_{1}$ & $a_{2}$ & $f_{1}$ & $f_{2}$ & $f_{3}$ & $f_{m}$ & $\cot (\theta)$ & HSR & OVT & WIF \\
\hline$[-]$ & {$[-]$} & {$[\mathrm{m}]$} & {$[\mathrm{m}]$} & {$[\mathrm{m}]$} & {$[\mathrm{Hz}]$} & {$[\mathrm{Hz}]$} & {$[\mathrm{Hz}]$} & {$[\mathrm{Hz}]$} & {$[-]$} & {$[-]$} & {$[-]$} & {$[-]$} \\
\hline BS01 & $2^{\text {nd }}$ & 0.65 & 0.09 & 0.01 & 0.400 & 0.438 & 0.038 & 0.419 & 35,50 & Yes* & Yes* & No \\
\hline BSO2 & $2^{\text {nd }}$ & 0.65 & 0.07 & 0.03 & 0.400 & 0.438 & 0.038 & 0.419 & 35,50 & Yes* & Yes* & No \\
\hline BS03 & $2^{\text {nd }}$ & 0.69 & 0.09 & 0.01 & 0.400 & 0.438 & 0.038 & 0.419 & 35,50 & Yes* & Yes* & Yes* \\
\hline BS04 & $2^{\text {nd }}$ & 0.69 & 0.07 & 0.03 & 0.400 & 0.438 & 0.038 & 0.419 & 35,50 & Yes* & Yes* & Yes* $^{*}$ \\
\hline
\end{tabular}

*very short test: 20 waves instead of $\sim 1000$ waves

\section{Instrumentation and measurements}

The data acquisition system DHI Wave Amplifier 102E was used to record surface elevations at 40 $\mathrm{Hz}$ by typical resistance type wave gauges (WG) and velocities by a Valeport (Model 802 with disc diameter $0.032 \mathrm{~m}$ ) electromagnetic current meter (ECM). The measurement set-up was different for each type of experiment:

- High spatial resolution tests (HSR): Here the complete dike geometry was included over the complete width of the flume. The concept of HSR experiments is to repeat a test several times for different locations of WG's (and ECM), to obtain a high spatial resolution dataset along the complete length of a beach slope, in this case the foreshore up to the dike toe.

A reference WG was kept at exactly the same location at all times to allow synchronization of all the repeated tests into one homogenous dataset per hydrodynamic condition. The attained repeatability was acceptable, with maximum differences of $0.003 \mathrm{~m}-0.040 \mathrm{~m}$ between the surface elevation measurement of the reference $\mathrm{WG}$ of each session and their mean over all sessions, and a standard deviation of $0.001-0.004 \mathrm{~m}$, depending on the wave conditions tested (see Fig. 3 ). 14 additional WG's were used at different locations along the foreshore between repeated tests, of which 7 were $0.30 \mathrm{~m}$ long and 8 were $0.50 \mathrm{~m}$ long. Seven gauges of each type were put together on separate rails (see Fig. 2b), which were moved by hand between repeated tests. The short wave gauges were deployed mainly in the inner surf zone up to the dike toe where the relatively short length still allows measurements of the surface elevation without clipping. They were first calibrated in deeper water and then flush mounted in the aluminum u-profile in the bed over the very shallow area, where an offset was applied. Conversely, the longest WG's were primarily used where the 
highest wave heights were expected: from the wave paddle over the shoaling and the outer surf zone. These were calibrated at their measurement locations. Inter-WG distances of $0.20 \mathrm{~m}-0.40 \mathrm{~m}$ were used for the 1:35 model scale tests and $0.28 \mathrm{~m}-0.56 \mathrm{~m}$ for the 1:25 scale tests. The shortest WGspacing was applied from the end of the shoaling zone across the surf zone where the wave transformation changes occur most rapidly, whereas the longest spacing was deemed sufficient from the foreshore slope toe to the shoaling zone (similar to the HSR experiments by Boers (1996)). These WG-spacings were considered to be sufficient to allow the decomposition of incident and reflected long waves following e.g. van Dongeren et al. (2007) or Almar et al. (2014). The amount of measured locations depended on the foreshore slope, where the mildest slope 1/80 required the most locations (i.e. 105, see Fig. 1e) and the steepest slope 1/20 required the least (i.e. 41, see Fig. 1a). To be able to measure all these locations, respectively 8 to 4 repeated tests were necessary.

The ECM was mounted vertically (i.e. disc horizontally, see Fig. 2b), allowing only the horizontal velocities (in $x-y$ directions) to be measured, with the $x$-axis directed along the flume. This was necessary, because the instrument shape did not allow an $x-z$ orientation of the sensor without disturbing the waves too much. It was always collocated with a WG to allow a decomposition of the incident and reflected long waves following Guza et al. (1984). Only one ECM was available, delivering as many data locations as repetitions of the test condition (see Fig. 1). The ECM had a maximum sampling frequency of $16 \mathrm{~Hz}$, but the analogue signal was recorded at $40 \mathrm{~Hz}$ in the WG data acquisition system, so that the 'clean' separately recorded digital signal at $16 \mathrm{~Hz}$ could be synchronized to the WG's afterwards.

- Overtopping tests (OVT): For these tests, only the foreshore slope and dike slope of $1 / 2$ was present in the main channel of the flume (see Fig. 2d) and no dike was present in the small channel (see Fig. 2e) to allow a simultaneous measurement of the incident wave conditions at the dike toe.

Seven wave gauges were located between the wave maker and the foreshore slope toe for (non-) linear reflection analysis purposes. Of those, three gauges were spaced according to the recommendations made by Mansard and Funke (1980) to allow a linear reflection analysis. The inter-WG distances of the remaining WG's were provided by Lykke Andersen (by e-mail comm.) to allow a non-linear reflection analysis (Røge Eldrup and Lykke Andersen, 2019), using the WaveLab software (Aalborg University, 2018b). Then another two WG's were placed at the toe of the dike: one in the main channel (with dike) and one in the small channel (without dike). Finally, an in-house made resistive wave gauge was located at the crest of the dike, which was used to help record individual overtopping events.

A basin with scale and pump was placed inside the wave flume behind the dike crest according to the weigh cell technique described by Victor and Troch (2010), which was necessary to allow measurements of individual wave overtopping volumes.

- Wave impact force tests (WIF): The dike geometry as described before was entirely present in the main channel of the flume (see Fig. 2c) and again, no dike was present in the small channel (see Fig. 2e) to allow a simultaneous measurement of the incident wave conditions at the dike toe.

The same WG set-up was put in place as the OVT tests, except for the WG at the dike crest. Instead, three WG's were flush mounted on top of the promenade to measure the flow depths and to be able to derive the flow velocity on the promenade. The WG's on top of the promenade were placed similarly as done by Streicher et al. (2016): one $0.05 \mathrm{~m}$ from the dike crest, one $0.05 \mathrm{~m}$ from the vertical wall and the middle one was $0.25 \mathrm{~m}$ from the vertical wall (at 1:25 model scale).

Two $3 \mathrm{~kg}$ load cells, of the 1042 model by Tedea-Huntleigh, were installed at the vertical wall to obtain two simultaneous measurements of the wave impact force. This was to investigate the variability of the wave force measurement along the width of the main channel in the flume. $0.10 \mathrm{~m}$ wide aluminum plates were attached to the load cells and were flush mounted with the plywood of the vertical wall. The load cells with aluminum plates were spaced $0.20 \mathrm{~m}$ from each other and were fixed as rigidly as possible via steel beams to the flume walls. Some gap width of a couple of millimeters was allowed with the plywood, to avoid them touching each other and influencing the measurement. No impact pressures were measured, because the pressure sensors at hand were too big compared to the expected flow layer thicknesses hitting the vertical wall at the model scales applied. 
- Incident wave conditions (IWC): In the set-up for these experiments, no dike was present over the complete width of the flume. Instead, passive wave absorption material was placed, minimizing the wave reflection (see Fig. 2f).

The target incident wave conditions to be generated were first calibrated in this set-up, because this set-up caused the least wave reflection due to the absence of the dike. This set-up was also useful to check the performance of the small channel in terms of measuring the incident wave conditions at the toe of the dike.

The WG positioning up to the dike toe was identical to those from the OVT and WIF experiments.
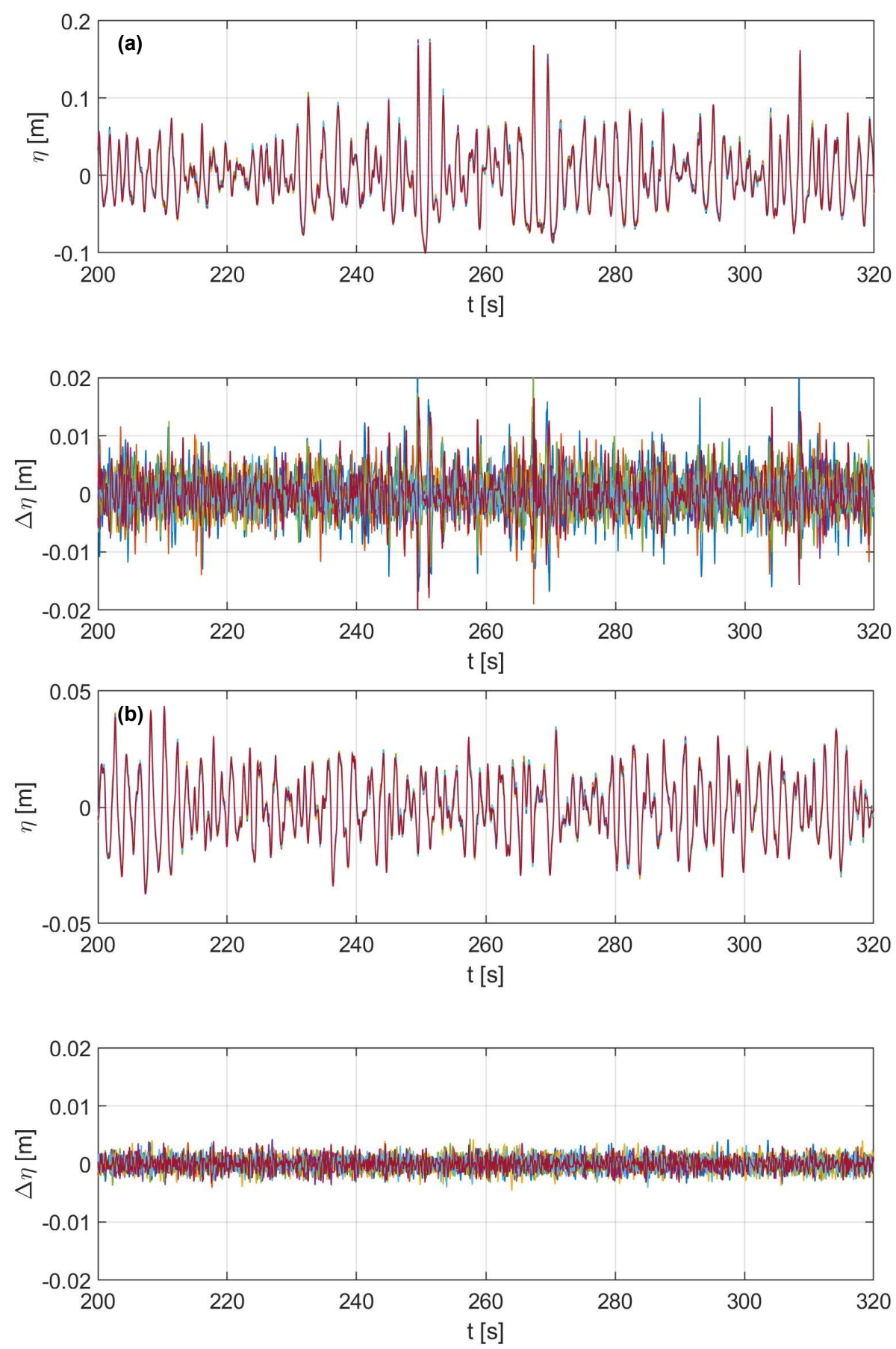

Figure 3. Surface elevation $\eta$ time series of six repeated tests measured by the reference wave gauge $(x=3.00$ $\mathrm{m}$ ) and the difference $\Delta \eta$ of each time series with their mean over all six repeated tests. Case with foreshore $1 / 50$ (scale 1:35), (a) for test RS06 $\left(|\Delta \eta|_{\max }=0.029 \mathrm{~m}, \sigma=0.003\right)$, and (b) for test RS11 $\left(|\Delta \eta|_{\max }=0.007 \mathrm{~m}, \sigma=\right.$ 0.001). 


\section{RESULTS}

Some first results are presented in this chapter, mainly to highlight the interesting research topics that will follow based on the experimental data generated.

\section{Wave transformation over the foreshore}

To investigate the short and long wave energy transformation over the foreshore, a separation of the total wave energy spectrum was made into those components. First, to calculate the variance-density spectra, one-minute or three-minute long (resp. for the short and long test durations), 50\% overlapping Hamming-windowed blocks were applied. Then the separation frequency $f_{\text {sep }}$ was chosen based on the location of the trough between the bulk of the infragravity wave energy and where the wave energy suddenly increases towards the primary peak of the spectrum at the reference location in front of the toe of the foreshore (e.g. $f_{\text {sep }}=0.28 \mathrm{~Hz}$ in Fig. $4 \mathrm{~b}$ ).

Thanks to the high spatial resolution measurements of the surface elevation along the complete foreshore, a detailed analysis is possible of the wave transformation up to the toe of the dike and of the effects the presence of the dike has on it. The cross-shore evolution of the short wave significant wave height $H_{m 0, h f}$ (hf: high frequency), the infragravity wave significant wave height $H_{m 0, l f}$ (lf: low frequency), the spectral wave period $T_{m-1,0}$ and the wave setup are presented in Fig. 5, for foreshore slope 1/50 (model scale 1:35) and the highest tested water level. Similar observations can be made to those obtained in experiments over a regular beach without dike (e.g. Ruessink et al., 2013), about the significant wave height (hf and lf) evolution over the foreshore. However, in the present case a steep-sloped dike was located in the inner surf zone close to the swash zone, and some differences can be observed in this area. One notable example is in the very shallow area in front of the dike, where the infragravity significant wave height strongly increases, instead of remaining constant or slightly decreasing towards the swash zone in the case of a beach without dike. This hints at a different reflection behavior of the infragravity waves due to the presence of the steep-sloped dike.

The cross-shore evolution of the wave spectrum is shown in Fig. 4. Again similar observations can be made compared to a beach without dike, where non-linear energy transfer occurs in the shoaling and surf zones towards the infragravity frequencies (here, $f<0.28 \mathrm{~Hz})$ and twice the peak frequency $(f \sim 1.0$ $\mathrm{Hz}$ ). However, at the toe of the dike two distinctive peaks appeared of similar energy content in the infragravity band and primary short wave band. This shows that for the highest tested water level, a nonnegligible energy content of the primary short waves was still present at the toe of the dike. These short waves are then also likely reflected strongly by the dike.

These initial observations will be further analyzed in the future by decomposing the wave field to the incident and reflected long waves and comparing the results more in-depth with a beach profile without a dike.
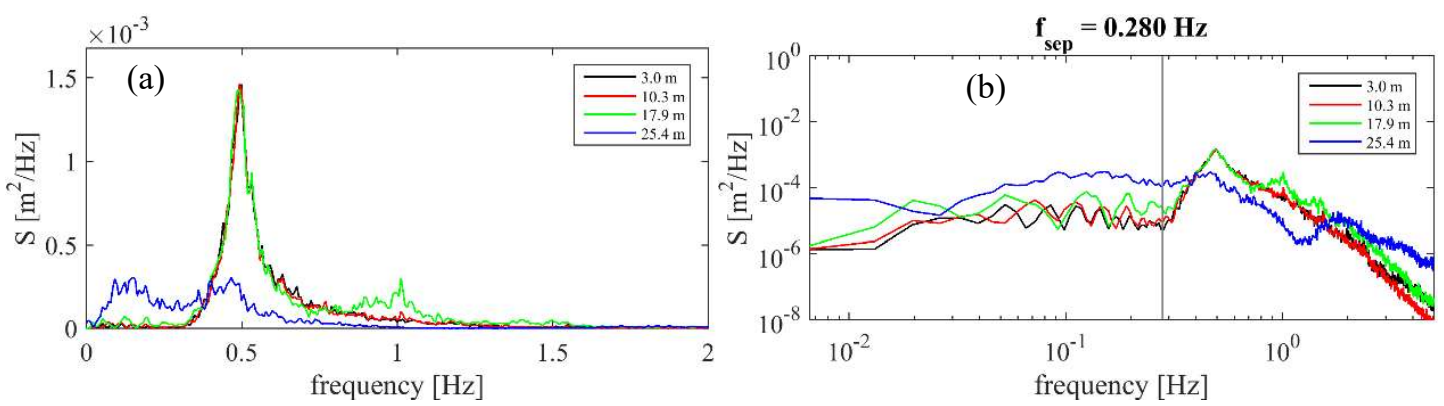

Figure 4. Spectral variance density $S$ over frequency $f$ of condition RS11 at four equidistant locations along the flume (foreshore 1/50 at model scale 1:35, see Fig. 1b and Fig. 3), starting at the reference wave gauge and ending at the wave gauge at the toe of the dike, (a) linear scale axes, (b) logarithmic scale axes, with indication of the separation frequency $f_{\text {sep }}$ (gray line). 


\begin{tabular}{|llllll|}
\hline O & RS06 & O & RS09 & O & RS11 \\
\hline
\end{tabular}
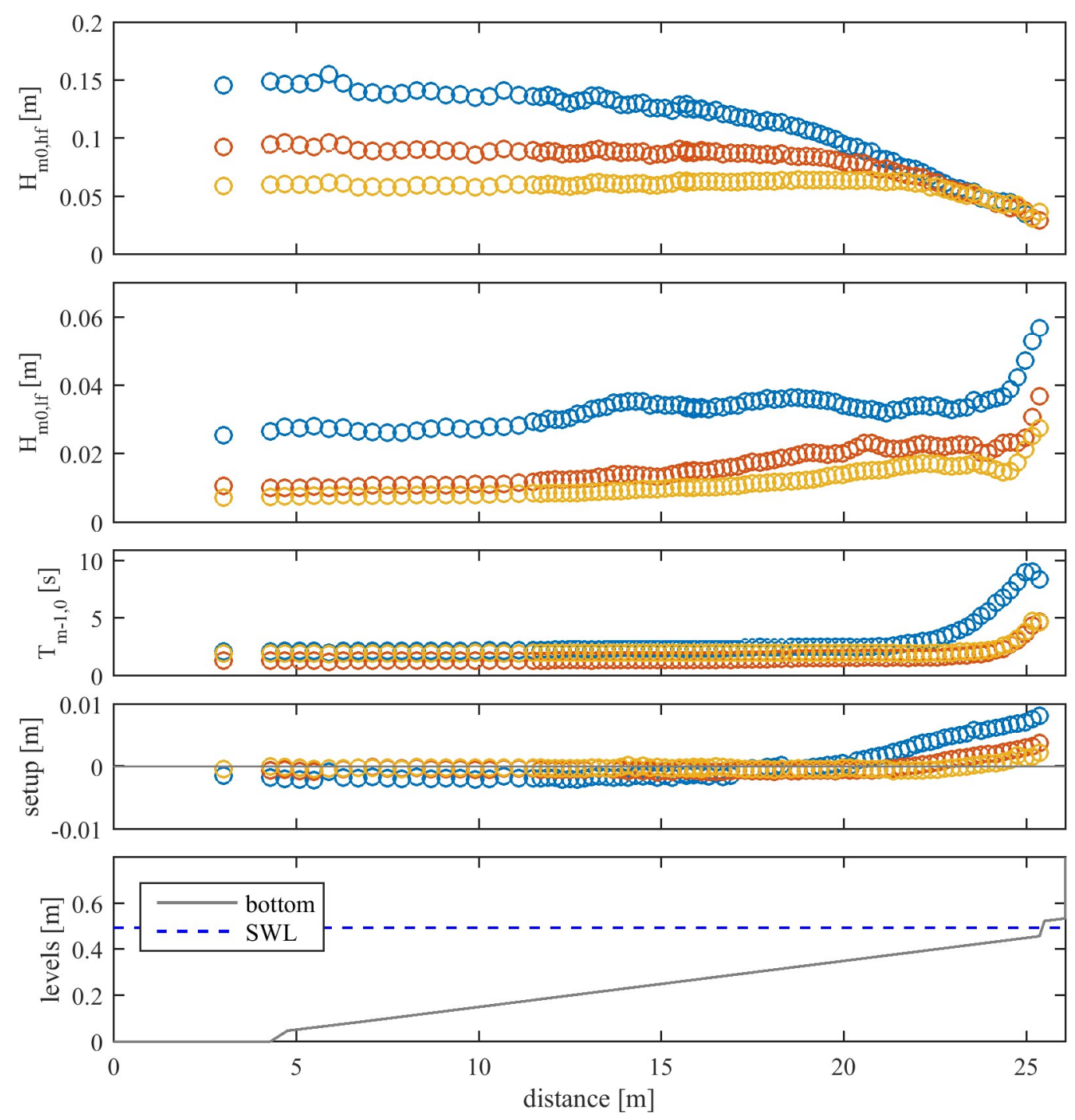

Figure 5. The wave characteristics measured over the complete foreshore (slope 1/50 at model scale 1:35), by way of repeated and combined HSR experiments, (a) the short wave (hf: high frequency) significant wave height $\boldsymbol{H}_{m 0, h f}$, (b) the infragravity wave (If: low frequency) significant wave height $\boldsymbol{H}_{m 0, f f}$, (c) the spectral wave period $T_{m-1,0}$, (d) the wave setup, and (e) the bottom profile with indication of the still water level (SWL).

\section{Spectral wave period at the dike toe}

Hofland et al. (2017) proposed for the first time a prediction formula for the spectral wave period $T_{m-1,0, t}$ at the toe of a dike fronted by a shallow $\left(1.0<h_{t} / H_{m 0, o}<4.0\right)$, very shallow $\left(0.3<h_{t} / H_{m 0, o}<1.0\right)$, to extremely shallow foreshore $\left(h_{t} / H_{m 0, o}<0.3\right)$ with a mild slope, defined by the following criterion:

$$
\theta T_{m-1,0, o} \sqrt{g / H_{m 0, o}}<0.62
$$

where $\theta$ is the foreshore slope angle (in radians), $T_{m-1,0, o}$ is the offshore spectral wave period, $g$ is the gravitational acceleration and $H_{m 0, o}$ is the offshore significant wave height. Their prediction formula for the spectral wave period $T_{m-1,0, t}$ is:

$$
\frac{T_{m-1,0, t}}{T_{m-1,0, o}}-1=6 \exp (-4 \tilde{h})+\exp (-\tilde{h})
$$

Eq. 2 estimates the spectral wave period in function of a relative water depth $\tilde{h}$ at the toe of the dike in which the foreshore slope $\cot \theta$ was incorporated: 


$$
\tilde{h}=\frac{h_{t}}{H_{m 0, o}}\left(\frac{\cot \theta}{100}\right)^{0.2}
$$

where $h_{t}$ is the water depth at the toe of the dike. The criterion of shallow foreshore is met (see Table 1), but the mild slope criterion, however, is not always fulfilled (see Table 3). Especially the steepest slope tested (i.e. 1/20) was not mild enough for Eq. 2 to be valid. The data of the mild slopes are compared with the prediction formula in Fig. 6. From this figure it can be concluded that Eq. (2) indeed provides a good estimation, albeit somewhat overestimated: the data are skirting the lower boundary of the confidence interval, especially for relative water depths larger than 0.25 . Preliminary analysis of the steeper $1 / 20$ and $1 / 35$ foreshore slopes, however, indicates a significant deviation of the prediction formula. This suggests there is still room for improvement in the prediction formula proposed by Hofland et al. (2017), at least for foreshore slopes steeper than 1/50, that might not strictly qualify as mild slopes anymore.

\begin{tabular}{|c|c|c|c|c|c|c|c|}
\hline Test ID & $h_{0}$ & $H_{m 0,0}$ & $T_{m-1,0,0}$ & $1 / 20$ & $1 / 35$ & $1 / 50$ & $1 / 80$ \\
\hline$[-]$ & [m] & [m] & [s] & {$[-]$} & {$[-]$} & {$[-]$} & {$[-]$} \\
\hline RS01 & 0.65 & 0.20 & 2.2 & 0.76 & 0.44 & 0.31 & 0.19 \\
\hline RS02 & 0.65 & 0.20 & 1.8 & 0.64 & 0.36 & 0.25 & 0.16 \\
\hline RS03 & 0.65 & 0.20 & 1.5 & 0.51 & 0.29 & 0.20 & 0.13 \\
\hline RS04 & 0.65 & 0.12 & 1.5 & 0.66 & 0.38 & 0.26 & 0.16 \\
\hline RS05 & 0.65 & 0.08 & 2.2 & 1.21 & 0.69 & 0.48 & 0.30 \\
\hline RS06 & 0.69 & 0.20 & 2.2 & 0.76 & 0.44 & 0.31 & 0.19 \\
\hline RS07 & 0.69 & 0.20 & 1.8 & 0.64 & 0.36 & 0.25 & 0.16 \\
\hline RS08 & 0.69 & 0.20 & 1.5 & 0.51 & 0.29 & 0.20 & 0.13 \\
\hline RS09 & 0.69 & 0.12 & 1.5 & 0.66 & 0.38 & 0.26 & 0.16 \\
\hline RS10 & 0.69 & 0.12 & 2.2 & 0.99 & 0.56 & 0.39 & 0.25 \\
\hline RS11 & 0.69 & 0.08 & 2.2 & 1.21 & 0.69 & 0.48 & 0.30 \\
\hline RS12 & 0.69 & 0.06 & 2.2 & 1.39 & 0.80 & 0.56 & 0.35 \\
\hline RS13 & 0.69 & 0.04 & 2.2 & 1.71 & 0.98 & 0.68 & 0.43 \\
\hline
\end{tabular}

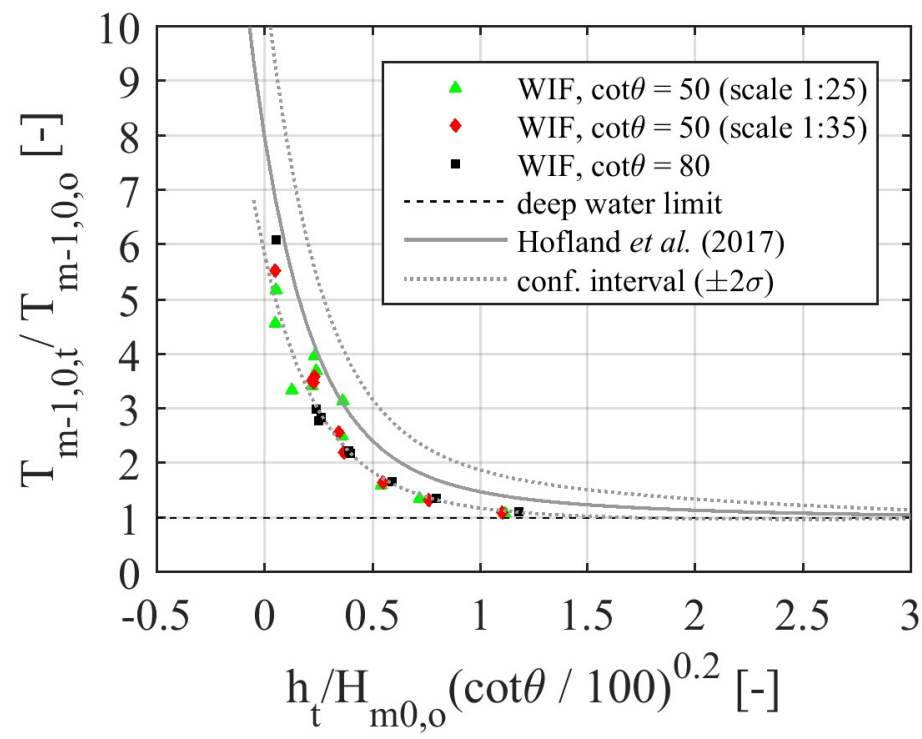

Figure 6. Dimensionless spectral wave period at the toe of the dike versus the relative water depth with slope correction. Experimental data compared to Eq. 2 for the test results in the small channel during the wave impact force (WIF) experiments with second order wave generation. The WIF small channel results were chosen to be plotted here, because the correspondence with the IWC tests was best.

\section{Wave overtopping}

The most recent semi-empirical model for wave overtopping over an impermeable dike with a shallow $\left(1.5<H_{m 0, o} / h_{t}<3.0\right)$ or very shallow foreshore $\left(H_{m 0, o} / h_{t}>3.0\right)$ is the formula of Van Gent (1999) recalibrated and adapted using the equivalent slope concept by Altomare et al. (2016): 


$$
\frac{q}{\sqrt{g H_{m 0, t}^{3}}}=10^{-0.791} \exp \left(-\frac{R_{c}}{H_{m 0, t}(0.33+0.022 m-1,0, t)}\right)
$$

in which $q$ is the mean overtopping discharge over the dike crest, $R_{c}$ the freeboard of the dike crest and the $\xi_{m-1,0, t}$ the breaker parameter, defined as:

$$
\xi_{m-1,0, t}=\frac{\tan \beta}{\sqrt{2 \pi H_{m 0, t}} / g T_{m-1,0, t}^{2}}
$$

where $\tan \beta$ is the equivalent slope, determined according to the procedure described by Altomare et al. (2016). Note the difference in definition of a (very) shallow foreshore by Van Gent (1999) compared to Hofland et al. (2017): (very) shallow foreshores by Van Gent (1999) are considered to be very to extremely shallow foreshores by Hofland et al. (2017). Additionally, Altomare et al. (2016) considered a criterion involving the wave steepness $\left(s_{m-1,0} \leq 0.01\right)$ to define a (very) shallow foreshore.

Eq. 5 is applicable for foreshore slopes between $1 / 20$ and $1 / 250$, dike slopes between $1 / 2$ and $1 / 6$, and a range of $h_{t} / H_{m 0, t}$ between (-0.88) and 2.38. All these criteria are met for all overtopping tests described in this paper. Therefore, the overtopping data of all tests can be used to validate Eq. 5 (see Fig. 7). Most of the data falls within the confidence interval, confirming the applicability of the prediction formula. In terms of differences between the foreshore slopes, it is notable that an influence of the foreshore slope is apparent, with the steepest foreshore slope delivering the highest overtopping discharges, especially for the higher dimensionless freeboards tested (i.e. > 3.0).

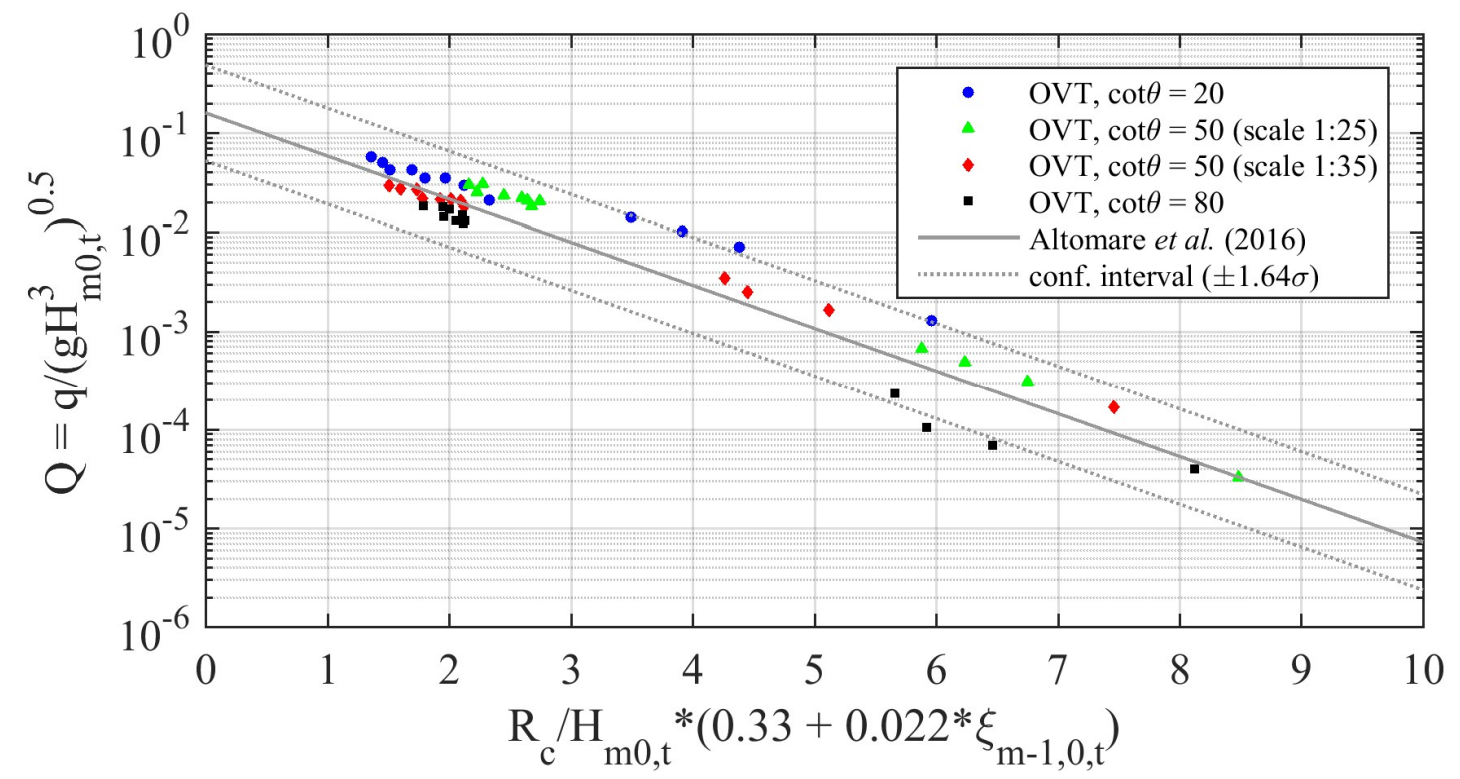

Figure 7. Semi-logarithmic plot (x-axis: linear scale, y-axis: logarithmic scale) of the dimensionless wave overtopping $Q$ in function of the dimensionless freeboard with shallow foreshore correction and equivalent slope. The experimental wave overtopping results (OVT) of the tests with second order wave generation for foreshore slopes $1 / 20,1 / 50$ and $1 / 80$ are compared to the prediction formula of Altomare et al. (2016) with the equivalent slope concept.

\section{Wave impact forces}

The raw wave force signals of both load cells were post-processed by first detrending the signal and then applying a Butterworth low-pass filter. The filter removed the spurious oscillations in the force signal due to the natural frequency response of the rigidly fixed load cell set-up (i.e. determined by a hammer test to be in the range of $40-50 \mathrm{~Hz}$ ) and the electrical frequency of $50 \mathrm{~Hz}$.

The processes involved in an overtopped wave bore impacting the vertical wall are described by Streicher et al. (2019). Here, two simultaneous wave impact force measurements are shown in Fig. 8a, for a couple of wave impacts during the highest energy wave condition test at the highest water level (RS06) over foreshore slope 1/50 (model scale 1:25). Although the general shape of the impact force 
signals are very similar between the load cells, some clear differences are visible indicating that wave impact force measurements in a wave flume have a variability along the fume width (see Fig. 8b). This uncertainty is caused by 3D model effects, where the long-crested wave bore is not perfectly hitting the vertical wall in a perpendicular way (apparent from visual observations and the time lag between the signals) and the inherent stochastic and 3D character of the process itself. This is important to know when e.g. using the data to validate numerical models.
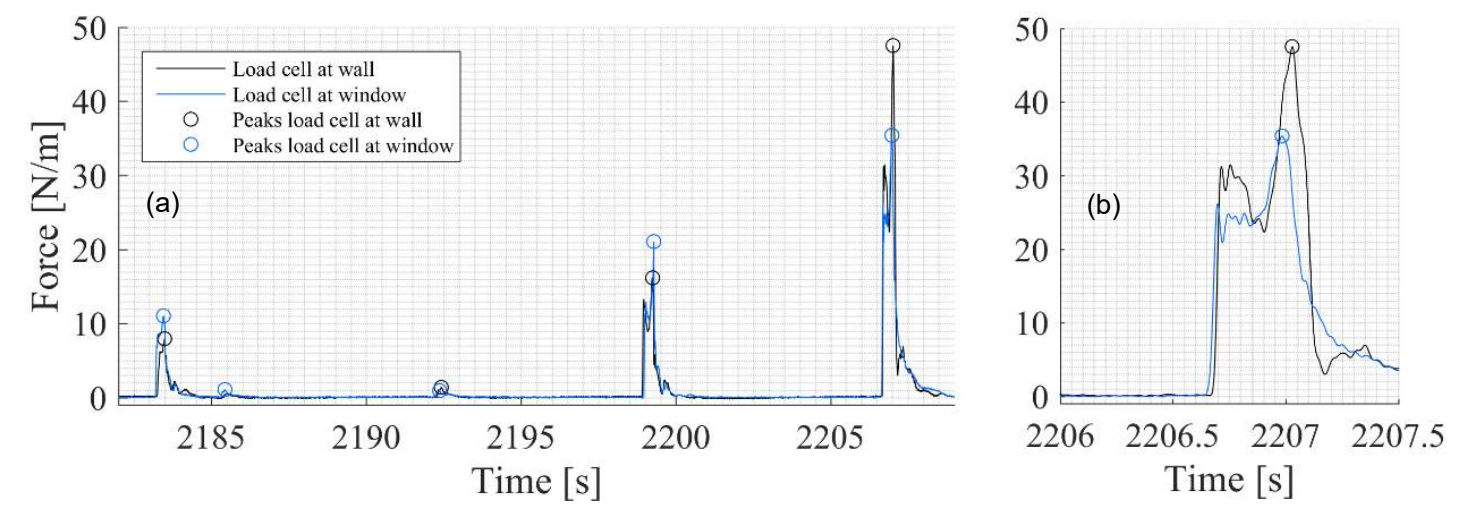

Figure 8. Comparison of the two load cell measurements, spaced $0.20 \mathrm{~m}$ from each other along the vertical wall on top of the dike. Impacts are shown for RS06, slope 1/50 at scale 1:25. (a) Overview of some impacts, (b) zoom to maximum force peak.

\section{CONCLUSIONS AND FUTURE WORK}

The 2D experiments conducted in the wave flume of Ghent University for the CREST project, resulted in a versatile dataset for the specific case of an impermeable, steep and low-crested dike with a fixed, very shallow and steeply to mildly sloped foreshore (i.e. slopes between $1 / 20-1 / 80$ ). The dataset includes highly detailed data of the cross-shore evolution of short and infragravity waves, wave overtopping over the dike crest and wave impact forces on a vertical wall placed on the promenade.

From the first results it has become clear that the foreshore slope influences the wave transformation up to the dike toe, where the influence is apparent compared to existing (semi-) empirical models for determination of the spectral wave period at the toe of the dike and wave overtopping at the dike crest. The high spatial resolution data show an increase in short and infragravity wave significant wave height in the very shallow area in front of the dike. The dataset also provides the potential to new insights into the effect of a dike located in the inner surf zone, near the swash zone. The comparison of both simultaneous load cell measurements have shown a variability, believed to be due to 3D model effects and the inherent stochastic character of the process of a wave bore hitting a vertical wall. This shows that a wave bore impact force measurement in a physical model does not provide a unique answer. This is important information when using the data to validate numerical models.

These results are subject to more in-depth analysis and form the basis for further research within the CREST project.

\section{ACKNOWLEDGMENTS}

The authors gratefully acknowledge the superb support of the technical staff of the UGent wave flume (Herman Van der Elst, Tom Versluys, Sam Meurez, David Derynck) for the experiments. The authors also wish to thank Hilario Castro Lara for his work on the post-processing of the physical model test data during his internship at UGent. This research is part of the CREST project (VLIZ, 2018), funded by the Flemish Agency for Innovation by Science and Technology.

\section{REFERENCES}

Aalborg University, 2018a. AwaSys webpage. www.hydrosoft.civil.aau.dk/awasys.

Aalborg University, 2018b. WaveLab webpage. www.hydrosoft.civil.aau.dk/wavelab.

Almar, R., Michallet, H., Cienfuegos, R., Bonneton, P., Tissier, M., Ruessink, G., 2014. On the use of the Radon Transform in studying nearshore wave dynamics, Coastal Engineering, 92, 24-30.

Altomare, C., Suzuki, T., Chen, X., T. Verwaest, T., Kortenhaus, A., 2016. Wave overtopping of sea dikes with very shallow foreshores, Coastal Engineering, 116, 236-257. 
Altomare, C., Verwaest, T., Willems, M., Vanneste, D., Suzuki, T., De Roo, S., 2018. Multi-directional wave basin for shallow foreshore applications, Proceedings of the 7th International Conference on the Application of Physical Modelling in Coastal and Port Engineering and Science (Coastlab18), Santander, Spain, May 22-26, 2018.

Boers, M., 1996. Simulation of a surf zone with a barred beach; Part 1: wave heights and wave breaking. TU Delft Report, No. 96-5.

Røge Eldrup, M., and Lykke Andersen, T., 2019. Estimation of incident and reflected wave trains in highly nonlinear two-dimensional irregular waves, Journal of Waterway, Port, Coastal, and Ocean Engineering, ASCE, 145(1).

Guza, R.T., Thornton, E.B., Holman, R.A., 1984. Swash on steep and shallow beaches, Proceedings of the Coastal Engineering Conference, 1984, 708-723.

Hofland, B., Chen, X., Altomare, C., Oosterlo, P., 2017. Prediction formula for the spectral wave period Tm-1,0 on mildly sloping shallow foreshores, Coastal Engineering, 123, 21-28.

Kamphuis, J.W., 1998. Long waves in flume experiments, Proceedings of 26th Conference on Coastal Engineering, 26, Copenhagen, Denmark, 1998.

Lykke Andersen, T., Clavero, M., Frigaard, P., Losada, M., Puyol, J.I., 2016. A new active absorption system and its performance to linear and non-linear waves, Coastal Engineering, 116, 236-257.

Mansard, E.P.D., Funke, E.R., 1980. The measurement of incident and reflected spectra using a least squares method, Proceedings of the Coastal Engineering Conference, 1980, 154-172.

MDK (Agency for Maritime and Coastal Services) - Coastal Division, FHR (Flanders Hydraulics Research), 2011. Masterplan Kustveiligheid - Kustveiligheidsplan (Coastal safety plan).

Ruessink, G., Michallet, H., Bonneton, P., Mouazé, D., Lara, J.L., Silva, P.A., Wellens, P., 2013. GLOBEX: Wave dynamics on a gently sloping laboratory beach, 7th International Conference on Coastal Dynamics, 1351-1362, 24-28 June, Bordeaux, France.

Streicher, M., Kortenhaus, A., Hohls, C., 2016. Analysis of post overtopping flow impacts on a vertical wall at the Belgian Coast, Proceedings of the 6th International Conference on the Application of Physical Modelling in Coastal and Port Engineering and Science (Coastlab16), Ottawa, Canada, May 10-13, 2016.

Streicher, M., Kortenhaus, A., Gruwez, V., Hofland, B., Chen, X., Hughes, S., Hirt, M., 2019. Prediction of dynamic and quasi-static impacts on vertical sea walls caused by an overtopped bore, Proceedings of 36th International Conference on Coastal Engineering (ICCE2018), Baltimore, Maryland.

Suzuki, T., Altomare, C., Verwaest, T., Trouw, K., Zijlema, M., 2014. Two-dimensional wave overtopping calculation over a dike in shallow foreshore by SWASH, Proceedings of 34th International Conference on Coastal Engineering (ICCE2014), Seoul, Korea.

van Dongeren, A.R., Battjes, J.A., Janssen, T.T., van Noorloos, J., Steenhauer, K., Steenbergen, G., Reniers, A., 2007. Shoaling and shoreline dissipation of low-frequency waves, Journal of Geophysical Research: Oceans, 112, C02011.

Van Gent, M.R.A., 1999. Physical model investigations on coastal structures with shallow foreshores: 2D model tests with single and double-peaked wave energy spectra, Delft Hydraulics/Waterbouwkundig Laboratorium.

Van der Meer, J.W., Allsop, N.W.H., Bruce, T., De Rouck, J., Kortenhaus, A., Pullen, T., Schüttrumpf, H., Troch, P., Zanuttigh, B., 2016. EurOtop, 2016. Manual on wave overtopping of sea defences and related structures. An overtopping manual largely based on European research, but for worldwide application, http://www.overtopping-manual.com/manual.html.

Victor, L., Troch, P., 2010. Development of a test set-up to measure large wave-by-wave overtopping masses, Proceedings on the Third International Conference on the Application of Physical Modelling to Port and Coastal Protection (Coastlab10), Barcelona, Spain, September 28-October $1,2010$.

VLIZ (Flanders Marine Institute), 2018. The CREST project webpage. http://www.crestproject.be/en. 